\section{TP Periodica Polytechnica Civil Engineering}

\author{
62(1), pp. 191-199, 2018 \\ https://doi.org/10.3311/PPci.10554 \\ Creative Commons Attribution (i)
}

\title{
Numerical Study on the Ultimate Deformation of RC Structural Walls with Confined Boundary Regions
}

\author{
Rafik Taleb ${ }^{1,2^{*}}$, Hidekazu Watanabe ${ }^{3}$, Susumu Kono ${ }^{4}$
}

Received 30 January 2017; Revised 05 April 2017; Accepted 05 May 2017

\begin{abstract}
For accurate assessment of performance levels in reinforced concrete $(R C)$ members, it is important to well define deformation limits at particular damage states. For RC walled building, investigation of the deformation limits of $R C$ structural walls is required to define limit states and corresponding limiting values. Numerical investigations were carried out on barbell shape and rectangular $R C$ walls with confined boundaries to evaluate response curves and ultimate deformations. A nonlinear 2D and 3D finite elements (FE) models were built in order to simulate the load-deformation relations under monotonic loading as well as cracking and damage patterns of previously tested walls. The FE models were able to simulate the backbone curves with good accuracy as well as the ability of boundary columns in reducing damage level. The 3D FE model simulated very well the ultimate deformation compared to $2 D$ models. A sectional fibre model combined with plastic hinge length and shear deformation component is proposed in order to simulate the backbone curves and the ultimate deformation with less computational cost compared to $3 D$ FE analysis. The model was able to provide relatively accurate backbone curves with very good estimation of ultimate drift.
\end{abstract}

\section{Keywords}

structural RC walls, confined boundary region, ultimate deformation, finite element analysis, sectional analysis

\footnotetext{
${ }^{1}$ Department of Environmental Science \& Technology, Tokyo Institute of Technology,

\section{Introduction}

Since the 1960s, considerable research as well as lessons learned from previous earthquakes, have led to improved understanding of the seismic behaviour of structural walls. Among the first reported observations concerning the seismic performance of structural walls were those following the 1960 Chilean earthquake [1], where the efficiency of structural walls in controlling structural damage during severe earthquakes was noted. Fintel [2] indicated that properly designed structural walls could be used effectively as the primary lateral load resisting system for both wind and earthquake loading in multistorey buildings. Today, reinforced concrete structural walls are frequently used as the primary component of the lateral load -resisting system in buildings located in earthquake prone regions because of their substantial contribution to building lateral stiffness and strength. When properly designed, these structural walls can also behave as ductile flexural members. To achieve this goal, designers should provide adequate strength and deformation capacity. Hence, several experimental and analytical studies were conducted to investigate the behaviour of RC structural walls under lateral loads in order for designers to predict their structural performance when subjected to severe seismic excitations [3-8]. A proper simulation of the ultimate deformation capacity of RC structural walls leads also to a rational determination of the behaviour factor or response modification factor used in seismic design codes.

Although the use of barbell shape RC walls with confined boundary columns was a common practice, modern architecture and design practices promoted the use of slender rectangular walls with the confidence that these planar walls with uniform wall thickness can be designed with adequate ductility than have been verified in past laboratory testing or past earthquakes. This trend towards more slender walls has been accelerated by the use of higher concrete strengths.

In the 2010 Chile Earthquake, severe damage happened to $\mathrm{RC}$ walls in numerous walled RC buildings leading to partial or total collapse so that structural engineers had to reconsider a false belief that structural walls always behave well. It was reported that lack of adequate confinement and detailing in end 
regions was one of the main causes of their damages, suggesting that more studies are needed to examine their seismic performance $[9,10]$.

A research program was undertaken in order to study the effects of end regions confinement on the seismic performance of moderate aspect ratio type of structural walls [11, 12]. Four $40 \%$-scale RC walls having different cross sectional configurations and transverse reinforcement at their confined end regions of were constructed and tested under lateral cyclic reversed loading. The test specimens included two specimens with boundary columns and two other specimens with rectangular shape section. It was shown that damaged regions due to concrete crushing in rectangular walls spread widely over the lower portion of the walls. The damage tended to spread horizontally towards wall centre and was limited in height. It was also shown that boundary columns in barbell shape walls can effectively enhance the wall performance by increasing its ultimate deformation capacity and reducing damage level in the wall panels.

\section{Review of experimental program}

\subsection{Wall Specimens and test procedure}

Experimental study were conducted on four $40 \%$ scale structural walls designed and constructed by changing the configuration of section (barbell-shape and rectangular sections) and the amount of shear reinforcement in confined regions [11]. The wall specimens were tested under reversal quasi-static cyclic loading with displacement control until collapse. A total axial force of $1500 \mathrm{kN}$ was applied constantly by two hydraulic jacks to keep the axial load level of 0.20 for confined region, corresponding to 0.11 for the total area of the section. Specimens BC40 and BC80 had confined boundary columns and NC40 and NC80 had no boundary columns but confined boundary regions instead with same thickness as for the wall panel (Fig. 1). The four specimens had same width $(1750 \mathrm{~mm})$, nearly same total section area $\left(2250 \mathrm{~cm}^{2}\right.$ for $\mathrm{BC} 40$ and $\mathrm{BC} 80$ and $2240 \mathrm{~cm}^{2}$ for $\mathrm{NC} 40$ and $\mathrm{NC} 80)$ as well as confined boundary region area $\left(625 \mathrm{~cm}^{2}\right.$ for $\mathrm{BC} 40$ and BC 80 and $666 \mathrm{~cm}^{2}$ for $\mathrm{NC40}$ and $\mathrm{NC} 80$ ). Figure 2 and Tab. 1 give detailing and properties of the wall specimens. Wall specimens were classified as intermediate aspect ratio walls and designed to fail in flexure, with shear safety factor defined as the ratio of shear capacity to flexural capacity more than 1.5. The flexural capacity, ${ }_{c} Q_{m u}$, were calculated based on a simplified wall design equation (Eq. 1) given by the standard for seismic evaluation of existing reinforced concrete buildings [13], and the shear capacity, ${ }_{c} Q_{s u}$, were calculated based on an empirical equation (Eq. 2) given by the Commentary of Structural Technique Standard for Buildings [14] as follow:

$$
{ }_{c} Q_{m u}=\left(a_{t} f_{y} l_{w}+0.5 a_{w v} f_{w v} l_{w}+0.5 N l_{w}\right) / a
$$

$$
{ }_{c} Q_{s u}=\left\{\frac{0.068 p_{t e}{ }^{0.23}\left(f^{\prime}{ }_{c}+18\right)}{\sqrt{M /(Q D)+0.12}}+0.85 \sqrt{f_{w h} p_{w h}}+0.1 \sigma_{0}\right\} t_{e} j
$$

Where $a_{t}, f_{y}$ are area and yield strength of longitudinal reinforcement in the wall boundary region, $a_{w v}, f_{w v}$ are area and yield strength of longitudinal web reinforcement, $l_{w}$ is length between the centers of boundary columns ( $0.9 \mathrm{D}$ for rectangular cross-section), $N$ is axial load, $a$ is shear span length, $p_{t e}$ is equivalent tensile reinforcement ratio $(\%)\left(=100 a_{t} / t_{e} d\right), d$ is effective length of wall $(=0.95 D), f_{c}$ ' is concrete compressive strength, $M /(Q D)$ is moment-to-shear ratio $(1 M /(Q D) \leq 3), f_{w h}$ is yield strength of horizontal web reinforcement, $p_{w h}$ is horizontal web reinforcement ratio, $\sigma_{0}$ is average axial stress for gross cross-sectional area, $t_{e}$ is equivalent wall thickness, $j$ is lever arm length $(=7 / 8 d)$ and $D$ is wall length.

During testing, each load increment was repeated two times at drift ratios (top horizontal displacement divided by height of lateral load application point) of $0.05 \%, 0.1 \%, 0.25 \%, 0.5 \%$, $0.75 \%, 1.0 \%, 1.5 \%, 2 \%$ and $4 \%$.

\section{Observed Damages and failure modes}

All specimens behaved in a flexural manner by yielding of the longitudinal reinforcement, reached the peak point and deformed until failure without significant degradation of lateral load carrying capacity. At $0.05 \%$ drift ratio, flexural cracks started to appear in the lower part of the tensile region. The number of flexural cracks increased along the confined regions height and progressed into flexural-shear cracks at drift ratio of $0.5 \%$ with the yielding of tensile longitudinal reinforcement. Crack openings in NC40/NC80 specimens were larger than those in BC40/BC80 specimens. Figure 3 shows crack patterns at peak load for all specimens. The longitudinal reinforcement in confined end regions yielded during the cycle of $\mathrm{R}= \pm 0.1 \%$ or $\pm 0.25 \%$ for both walls configuration, although the yielding for NC's specimens tended to happen earlier than for BC's specimens. BC40 and BC80 showed no degradation of load carrying capacity until the failure while NC40 and NC80 showed some degradation after reaching peak load due to crushing of core concrete that quickly followed after the peak point. It was remarkable that $\mathrm{BC} 40$ and $\mathrm{BC} 80$ could further sustain load capacity for a larger interval of deformability compared to NC40 and NC80. The ultimate failure was caused by crushing of confined concrete and buckling of longitudinal reinforcement in the compression zone.

The performance of wall with boundary columns was better than that of rectangular walls with similar shear span to wall length ratio in terms of drift capacity. Boundary columns also showed the ability to reduce damage level in wall panel since they carry a large amount of axial force which reduces axial stress level in wall panels. 

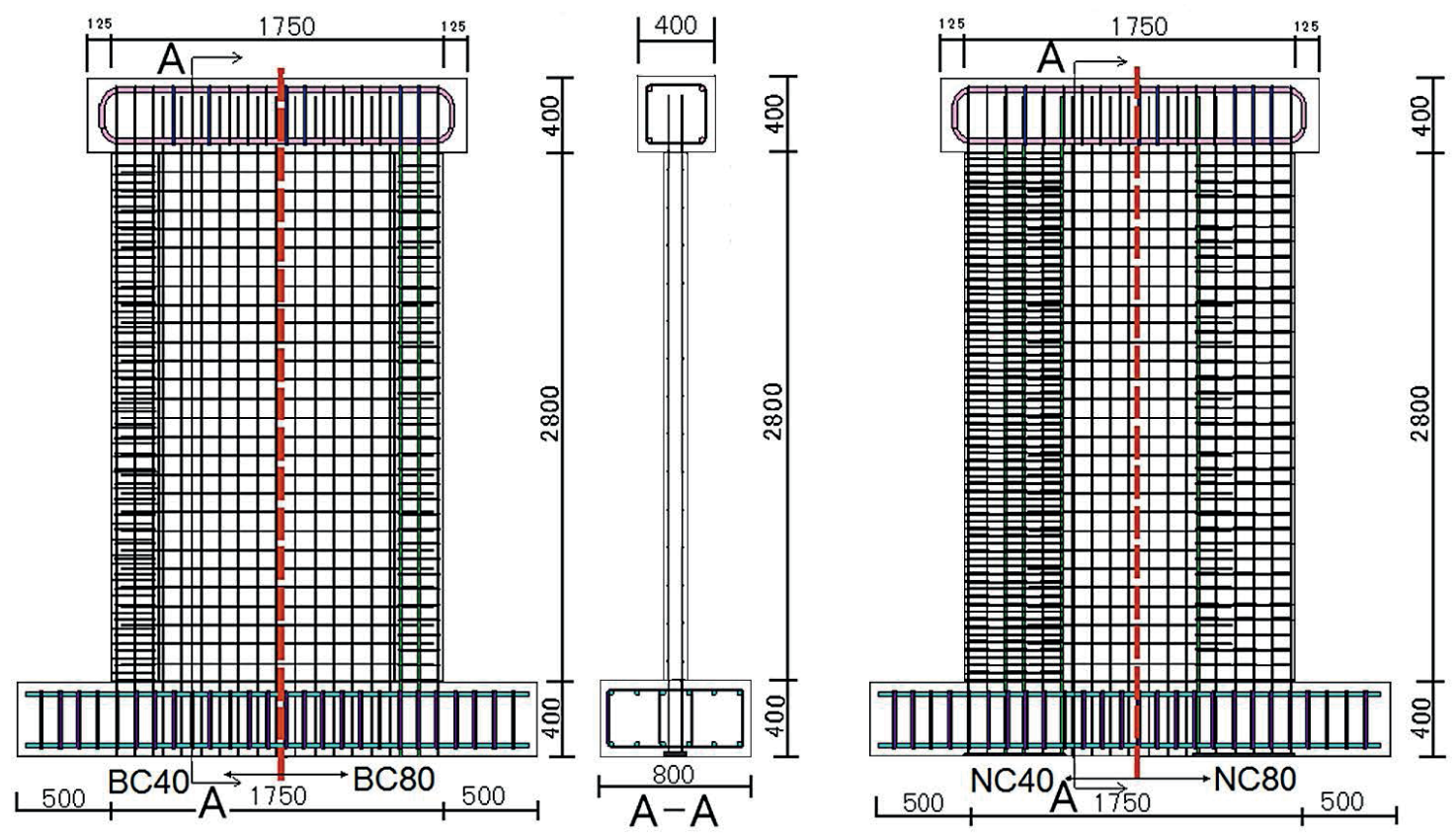

Fig. 1 Vertical reinforcement layouts of wall specimens
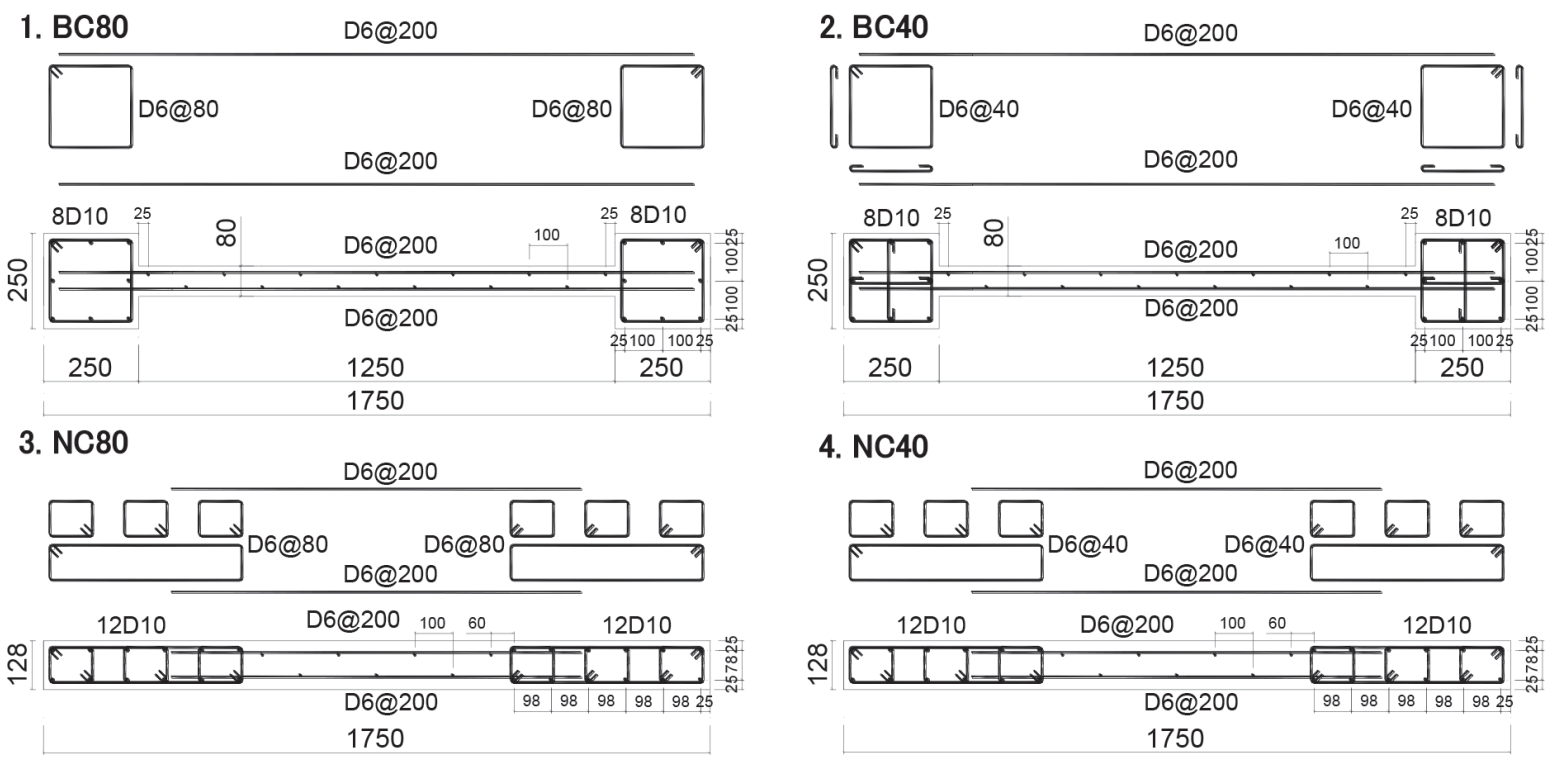

Fig. 2 Cross sections and reinforcement details

Table 1 Properties of wall specimens.

\begin{tabular}{|c|c|c|c|c|c|c|c|c|c|}
\hline \multirow{2}{*}{ Specimen } & \multirow{2}{*}{$\begin{array}{c}h_{w} / l_{w} \\
(\mathrm{~mm})\end{array}$} & \multirow{2}{*}{$\begin{array}{c}a_{s} \\
\text { (Shear span) }\end{array}$} & \multicolumn{2}{|c|}{ Confined end regions } & \multicolumn{2}{|c|}{ Wall panel } & \multirow{2}{*}{$N / A f_{c}$, } & \multirow{2}{*}{$\begin{array}{l}{ }_{c} Q_{m u} \\
(\mathrm{kN})\end{array}$} & \multirow{2}{*}{$\begin{array}{l}{ }_{c} Q_{s u} \\
(\mathrm{kN})\end{array}$} \\
\hline & & & $A_{c h}\left(\mathrm{~mm}^{2}\right)$ & $p_{l}, \%$ & $t_{w}(\mathrm{~mm})$ & $p_{w h}=p_{w v}, \%$ & & & \\
\hline $\mathrm{BC} 40 / \mathrm{BC} 80$ & 1.6 & 1.71 & $250 \times 250$ & 0.91 & 80 & 0.40 & 0.13 & 532 & 761 \\
\hline $\mathrm{NC} 40 / \mathrm{NC} 80$ & $(2800 / 1750)$ & $(3000 \mathrm{~mm})$ & $128 \times 520$ & 1.29 & 128 & 0.25 & 0.11 & 586 & 867 \\
\hline
\end{tabular}

Table 2 Measured mechanical properties of concrete and reinforcement.

\begin{tabular}{lccccccc}
\hline Specimen & \multicolumn{3}{c}{ Concrete } & \multicolumn{3}{c}{ Reinforcement } \\
& $\begin{array}{c}\text { Compressive } \\
\text { strength } \\
(\mathrm{MPa})\end{array}$ & $\begin{array}{c}\text { Young's modulus } \\
(\mathrm{GPa})\end{array}$ & $\begin{array}{c}\text { Splitting strength } \\
(\mathrm{MPa})\end{array}$ & Reinf. bars & $\begin{array}{c}\text { Yield strength } \\
(\mathrm{MPa})\end{array}$ & $\begin{array}{c}\text { Young's modulus } \\
(\mathrm{GPa})\end{array}$ & $\begin{array}{c}\text { Tensile strength } \\
(\mathrm{MPa})\end{array}$ \\
\hline BC80/BC40 & 59.5 & 30.9 & 5.10 & D6 & 387 & 189 & 496 \\
NC80/NC40 & 52.5 & 30.1 & 3.66 & D10 & 377 & 194 & 533 \\
\hline
\end{tabular}



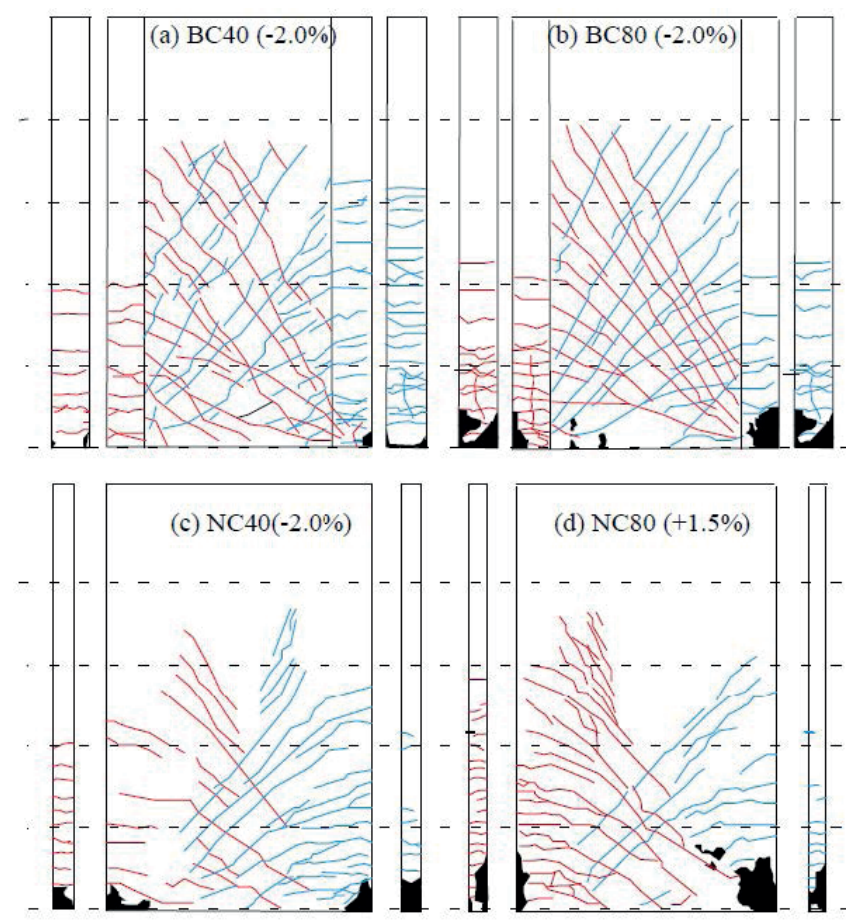

Fig. 3 Crack patterns at peak load

\section{Nonlinear Finite Elements Analysis 4.1 2D Finite Element Analysis}

Numerical analyses were conducted under monotonic loading to investigate the envelope of lateral load response of the tested walls as well as the damage distribution. The 2D nonlinear analysis was conducted using FE program FINAL [15]. Figure 4 shows FE mesh for BC's specimens. Four-node plane stress quadrilateral elements were used to model the RC walls. The foundation and loading beams were assumed to behave elastically. All nodes at the bottom of the foundation beam were pin-supported to restrain vertical and lateral displacement. The constant axial loads on the top of boundary regions were applied in the first step and then the lateral load was applied at the loading beam centre point under displacement control.

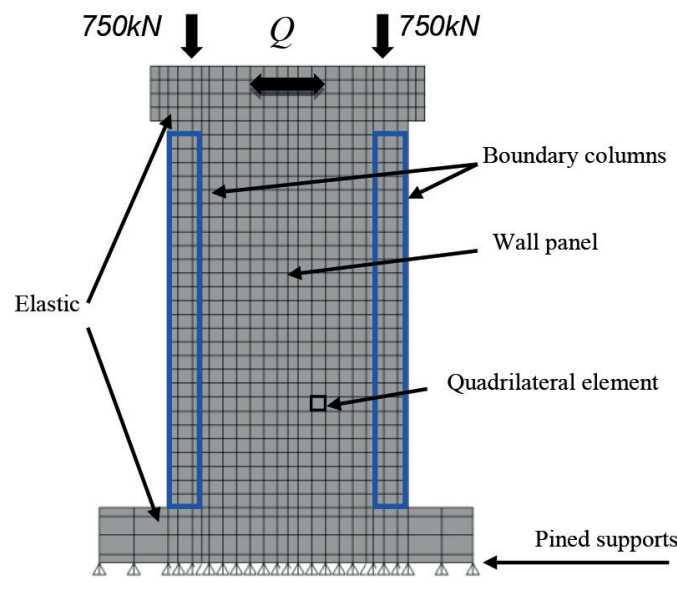

Fig. 4 FE mesh for BC's specimens
Truss elements were used to model the vertical reinforcements in confined boundary regions considering bond effect which was modelled using Elmorsi model [16]. Stress-strain relation for reinforcement material follows Ciampi's model [17]. All Horizontal and vertical reinforcements in wall panels as well as transverse reinforcement in confined regions were smeared assuming a perfect bond. The modified Ahmad model [18] for the compressive stress-strain relation of concrete was used for both ascending and descending branches for confined and unconfined concrete. Mechanical properties of material used in the analysis are thus given in Tab. 2. The Kupfer-Gerstle's failure criterion was adopted for failure in biaxial compression and in tension-compression [19]. The Naganuma model was adopted for concrete tension stiffing [20]. Uniaxial tensile strength is used for judging cracks under uniaxial and biaxial tension. Stress-strain relationship is assumed to be linear up to cracking. The smeared crack model with a fixed angle concept was used to express cracking of concrete. The shear transfer model after cracking proposed by Naganuma was used [21].

Figure 5 shows cyclic lateral load-drift angle relationships obtained experimentally and monotonic envelop obtained by $2 \mathrm{D}$ FE analysis. Table 3 compares damage characteristic points: flexural cracking, yielding of longitudinal reinforcement in confined end regions, and peak load derived from experiment and monotonic FE analysis. The ultimate deformation was defined by either $20 \%$ degradation of load carrying capacity from the peak load or the maximum observed drift. The results show that the model is capable of simulating the entire steps of the nonlinear behaviour of the concrete wall such as initial stiffness, cracking, steel yielding, and peak load with good accuracy.

Table 4 shows comparison of ultimate deformation point between experimental and 2D FE analysis. Although the model tends to underestimate the ultimate deformation points, the model well captures their trend since ultimate drift of BC's specimens are larger than those of NC's specimens, and that for the same wall configuration, ultimate drift in specimens with $40 \mathrm{~mm}$ transverse reinforcement spacing is larger than those with $80 \mathrm{~mm}$ spacing.

Figure 6 illustrates cracks distribution and damage pattern at ultimate. Crack distribution is less spread in the case of walls with boundary elements compared to that of rectangular walls. Damage for walls with boundary column is concentrated at the outside bottom of boundary columns, while for walls without boundary damage extended along the bottom of confined regions. This is due to the fact that boundary columns carry a large amount of axial force to reduce axial stress level of wall panels to reduce their damage. The built model predicted damage pattern quite well, and has also predicted the ability of boundary columns in reducing damage level and crack distribution. 


\subsection{D Finite Element Analysis}

Numerical analyses with 3D FE model were also conducted under monotonic loading to verify the ability of 3D modelling for the estimation of ultimate drift, since 2D model was not able to well capture it. In 3D FE model, eight-node elements were used to model the $\mathrm{RC}$ walls. The foundation and loading beams were assumed to behave elastically. Similar constitutive material models used for $2 \mathrm{D}$ analysis were also used for $3 \mathrm{D}$ analysis. All reinforcements, including longitudinal reinforcing bars in confined regions were smeared assuming a perfect bond with concrete. The analysis employed Ottosen's four-parameter model [22] to define the failure criterion of concrete. Figure 7 shows cyclic lateral load-drift angle relationships obtained experimentally and monotonic envelop obtained by 3D FE analysis. The analysis tends to simulate slightly higher initial stiffness. However, the analytical backbone curve agrees very well with the experimental one until ultimate drift point, especially in positive loading direction. Similarly to 2D models, 3D models could predicted the ability of boundary columns in reducing damage level and crack distribution, since crack distribution is less spread in the case of walls with boundary elements compared to that of rectangular walls (Fig. 8).
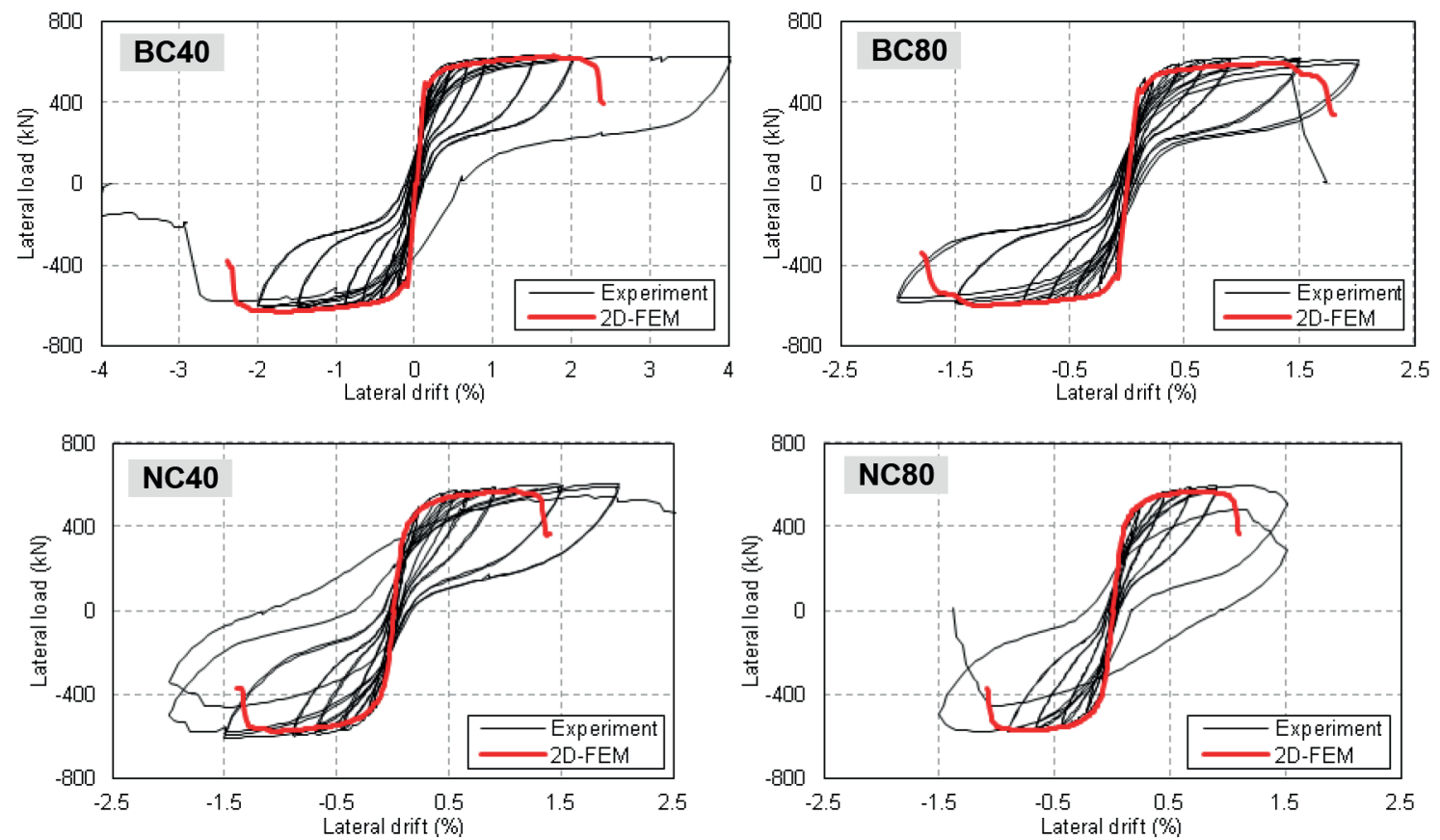

Fig. 5 Experimental hysteretic [11] and 2D-FEM monotonic lateral load - drift angle relations
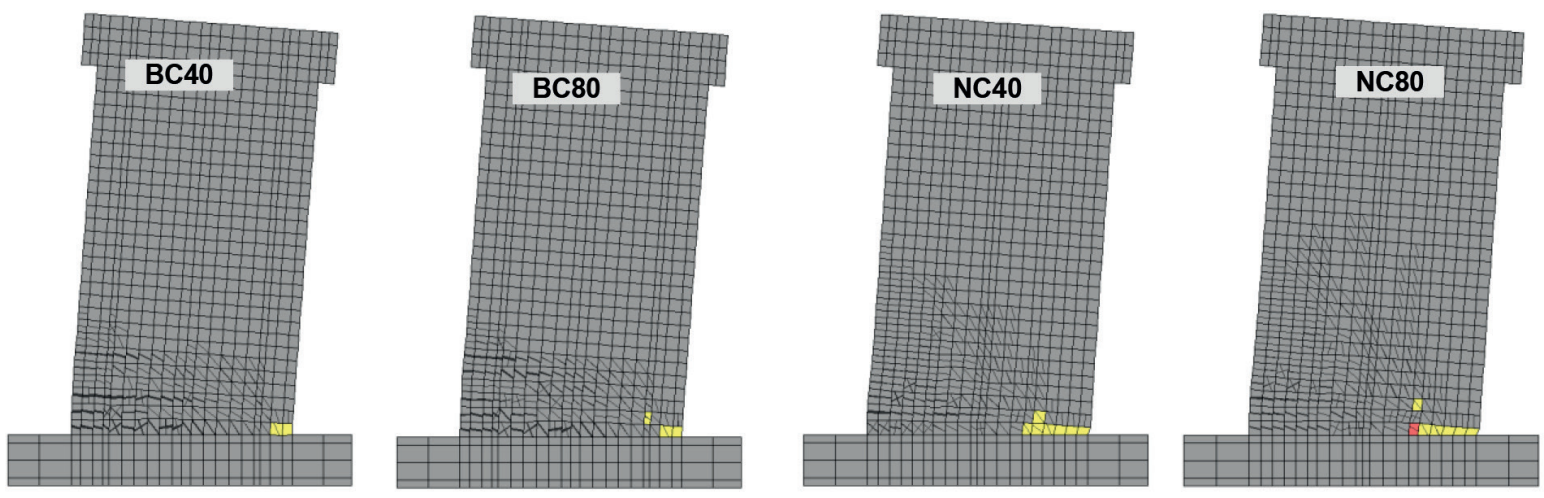

Fig. 6 Damage pattern 1.5\% lateral drift ratio

Table 3 Comparison of characteristic damage points

\begin{tabular}{|c|c|c|c|c|c|c|c|c|c|c|c|c|}
\hline \multirow{3}{*}{ Specimen } & \multicolumn{4}{|c|}{ Flexural cracking point } & \multicolumn{4}{|c|}{ Steel yielding point } & \multicolumn{4}{|c|}{ Peak load point } \\
\hline & \multicolumn{2}{|c|}{ Experiment } & \multicolumn{2}{|c|}{ Analysis } & \multicolumn{2}{|c|}{ Experiment } & \multicolumn{2}{|c|}{ Analysis } & \multicolumn{2}{|c|}{ Experiment } & \multicolumn{2}{|c|}{ Analysis } \\
\hline & $\begin{array}{l}R(\%) \\
(+) /(-)\end{array}$ & $\begin{array}{l}Q(\mathrm{kN}) \\
(+) /(-)\end{array}$ & $\begin{array}{c}R \\
(\%)\end{array}$ & $\underset{(\mathrm{kN})}{Q}$ & $\begin{array}{l}R(\%) \\
(+) /(-)\end{array}$ & $\begin{array}{l}Q(\mathrm{kN}) \\
(+) /(-)\end{array}$ & $\begin{array}{c}R \\
(\%)\end{array}$ & $\underset{(\mathrm{kN})}{Q}$ & $\begin{array}{l}R(\%) \\
(+) /(-)\end{array}$ & $\begin{array}{l}Q(\mathrm{kN}) \\
(+) /(-)\end{array}$ & $\begin{array}{c}R \\
(\%)\end{array}$ & $\underset{(\mathrm{kN})}{Q}$ \\
\hline $\mathrm{BC} 40$ & $0.12 /-0.10$ & $443 /-441$ & 0.06 & 346 & $0.29 /-0.25$ & $562 /-521$ & 0.11 & 546 & $1.41 /-1.47$ & $634 /-608$ & 1.75 & 633 \\
\hline $\mathrm{BC} 80$ & $0.08 /-0.07$ & $418 /-338$ & 0.07 & 400 & $0.26 /-0.33$ & $487 /-507$ & 0.11 & 546 & $1.17 /-1.45$ & $633 /-592$ & 1.29 & 599 \\
\hline $\mathrm{NC} 40$ & $0.07 /-0.09$ & $328 /-379$ & 0.05 & 231 & $0.19 /-0.20$ & $478 /-449$ & 0.17 & 505 & $1.91 /-1.46$ & $606 /-604$ & 1.06 & 573 \\
\hline NC80 & $0.09 /-0.08$ & $334 /-331$ & 0.05 & 231 & $0.30 /-0.12$ & $467 /-332$ & 0.17 & 505 & $1.16 /-0.87$ & $598 /-578$ & 0.69 & 570 \\
\hline
\end{tabular}


Table 4 Comparison between experiment and 2D-FEM analysis for ultimate drift point

\begin{tabular}{lccc}
\hline & \multicolumn{3}{c}{ Ultimate drift point } \\
\cline { 2 - 4 } Specimen & Experiment & Analysis & Ratio \\
& $R_{\text {exp }}(\%)(+) /(-)$ & $R_{\text {ana }}(\%)$ & $R_{\text {exp }} / R_{\text {ana }}$ \\
\hline BC40 & $4.00 /-2.75$ & 2.32 & 1.45 \\
BC80 & $2.00 /-2.00$ & 1.72 & 1.16 \\
NC40 & $2.38 /-2.00$ & 1.32 & 1.66 \\
NC80 & $1.50 /-1.50$ & 1.07 & 1.40 \\
\hline
\end{tabular}

Note: The ratio of experimental and analytical lateral drift was calculated based on the average value of the experimental ultimate drift between positive and negative loading directions.

Table 5 shows comparison of ultimate deformation point between experimental and 3D FE analysis. The model estimates very well the ultimate deformations of the tested wall specimens.
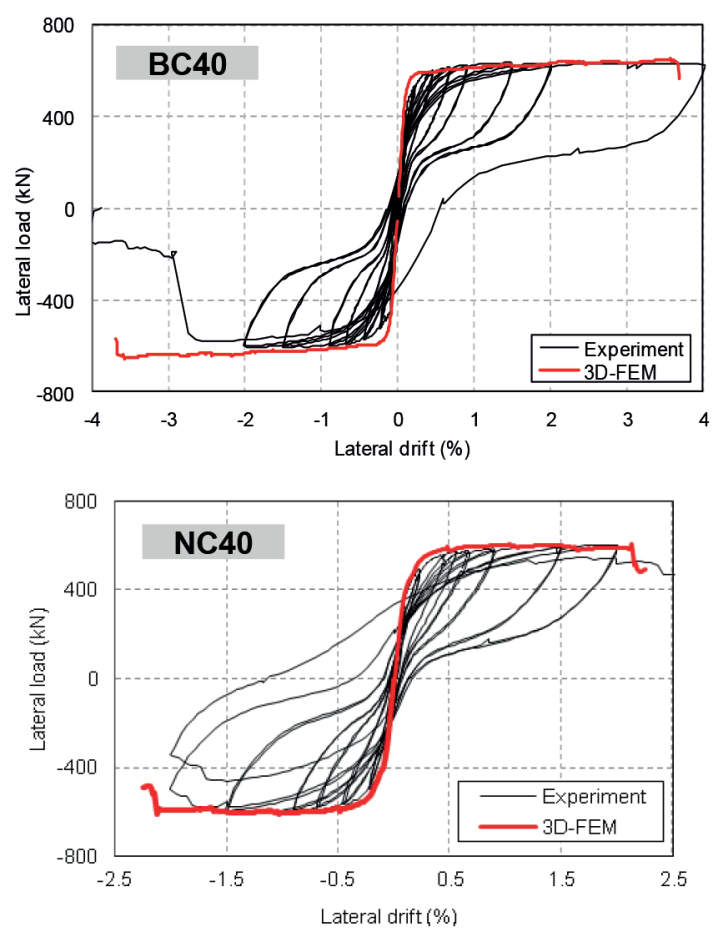

Fig. 7 Experimental hysteretic [11] and 3D-FEM lateral load - drift angle relations
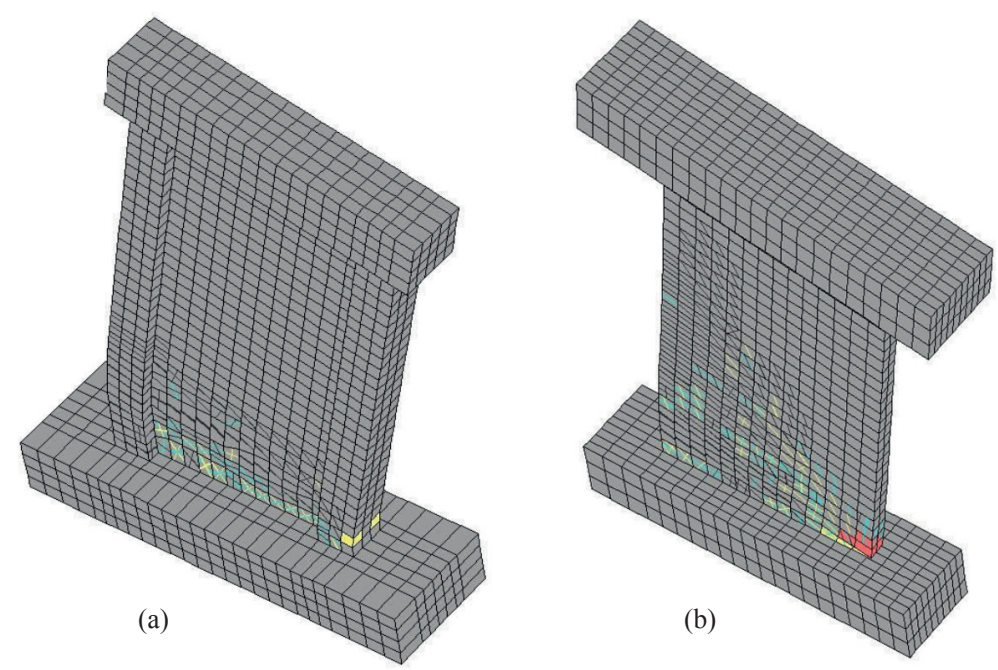

Fig. 8 Damage pattern at 1.5\% drift ratio of (a) BC80 and (b) NC80

\section{Fibre Sectional Analysis}

A sectional fibre model analysis was conducted to compute the backbone lateral load - drift angel relations as well as to estimate the ultimate lateral drift based on the plastic hinge length and moment-curvature analysis (Fig. 9). The wall section was divided into small concrete elements along the width direction and each longitudinal reinforcing bar was modelled as an independent steel element (Fig. 10a). The monotonic envelope curve for plain and confined concrete in compression follows the modified Kent and Park model [23]. The tensile contribution of concrete was neglected. The numerical model used for reinforcing steel was based on Menegotto-Pinto model as extended by Filippou et al. [24] to include isotropic strain hardening effects.
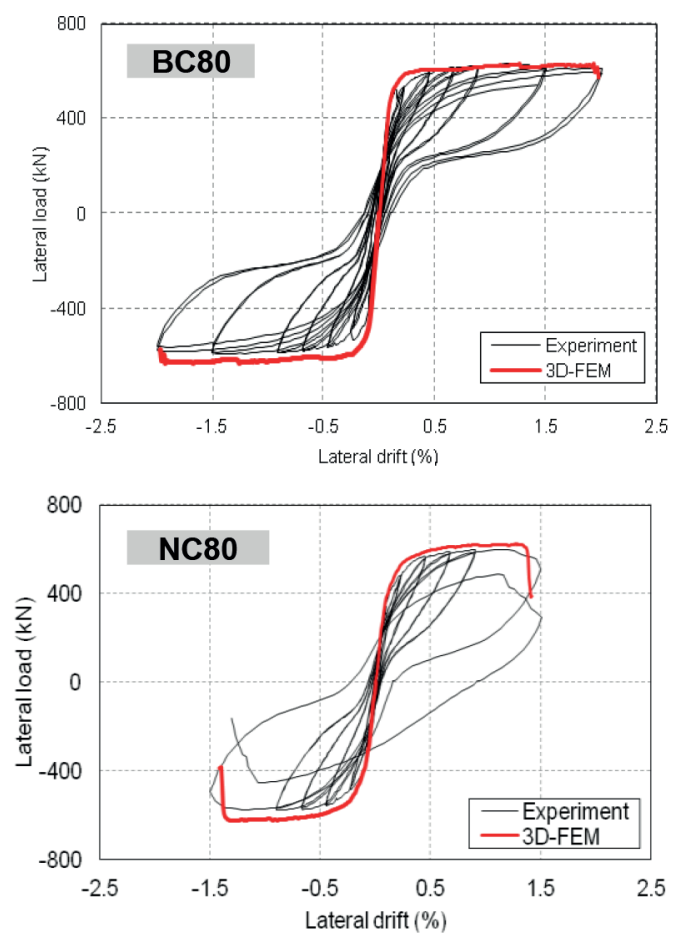
Table 5 Comparison between experiment and 3D-FEM analysis for ultimate drift point

\begin{tabular}{cccc}
\hline \multirow{3}{*}{ Specimen } & \multicolumn{3}{c}{ Ultimate drift point } \\
\cline { 2 - 4 } & Experiment & Analysis & Ratio \\
& $R_{\text {exp }}(\%)(+) /(-)$ & $R_{\text {ana }}(\%)$ & $R_{\text {exp }} / R_{\text {ana }}$ \\
\hline BC40 & $4.00 /-2.75$ & 3.69 & 0.92 \\
BC80 & $2.00 /-2.00$ & 1.97 & 1.02 \\
NC40 & $2.38 /-2.00$ & 2.22 & 0.99 \\
NC80 & $1.50 /-1.50$ & 1.43 & 1.05 \\
\hline
\end{tabular}

Note: The ratio of experimental and analytical lateral drift was calculated based on the average value of the experimental ultimate drift between positive and negative loading directions.

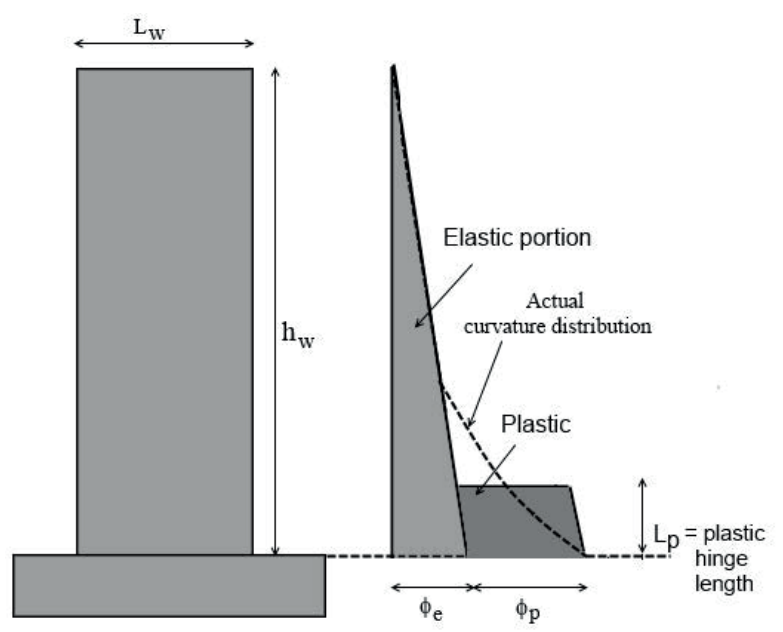

Fig. 9 Curvature and deformation distribution along the wall height

The total drift is obtained by the sum of the flexural component and the shear component. The flexural component is computed by Eq. (3) as the sum of the elastic and the plastic components based on the curvature distribution. The curvature is divided into elastic and plastic curvatures, and each curvature was used to derive elastic drift, $\delta_{e}$, and plastic drift, $\delta_{p}$, as Eq. (4) and Eq (5).

$$
R_{f}(\%)=\frac{\delta_{f e}+\delta_{f p}}{H} \times 100
$$

with,

$$
\begin{gathered}
\delta_{f e}=Q \cdot H^{3} /(3 E I) \\
\delta_{f p}=\frac{1}{2} \varphi_{p} l_{p}^{2}+\varphi_{p} l_{p}\left(H-l_{p}\right)
\end{gathered}
$$

Where $Q$ is the lateral load, $H$ the wall height (3000mm), $E$ Young's modulus of concrete, $I$ the second moment of inertia of the wall section, $\phi_{p}$ the plastic curvature, $l_{p}$ the plastic hinge length.

The plastic hinge length corresponds to the yielding of longitudinal reinforcement and plastic curvature distribution. The plastic hinge length calculations significantly influence the estimation of the force-displacement response of that wall in the inelastic region. Existing plastic hinge length equations are usually proposed for RC columns and applicable for RC walls. Observations from the tested walls have shown that the damage region was limited in height and tends to spread more horizontally toward wall centre [11]. Similarly, observations from previous experimental studies indicate that the compressive failure region is quite limited within a height of about 2.5 times the wall thickness $[25,26]$. Hence, the plastic hinge length was estimated to be 2.5 times the wall panel thickness.

The shear deformation of walls is estimated using the empirical equation developed by Beyer et al. [27] as given by Eq. 6 . This empirical equation was developed based on a series of experimental and analytical studies of slender reinforced concrete walls under seismic loading. The shear deformation component was added to the flexural component to obtain the total deformation without considering flexure-shear interaction.

with

$$
\delta_{s}=1.5 \delta_{f}\left(\frac{\varepsilon_{m}}{\varphi \tan \beta}\right) \frac{1}{H_{w}}
$$

$$
\tan \beta=\frac{j_{d}}{V}\left(f_{l} t_{w}+\frac{A_{s w} f_{y w}}{s}\right) \quad\left(\beta \leq 90^{\circ}\right)
$$

where, $\delta_{f}$ is the flexural lateral displacement, $\beta$ is the crack angle, $\varepsilon_{m}$ is the axial strain at the centre of the wall section, $\phi$ is the curvature of the wall section, $j_{d}$ is the lever arm between compression and tensile resultants, $V$ is the shear force, $f_{l}$ is the tensile strength orthogonal to the crack, $t_{w}$ is the wall thickness, $A_{s w}$ is the area of the shear reinforcement, $f_{y w}$ is the yield strength of shear reinforcement, and $s$ is the spacing of shear reinforcement.

The ultimate drift was computed based on the limit compressive strain, $\varepsilon_{c u}$, proposed by Mander et al. [28].

$$
\varepsilon_{c u}=0.004+\frac{1.4 \rho_{s} f_{y h} \varepsilon_{s m}}{f_{c}^{\prime}}
$$

where $\rho_{s}$ is the volumetric ratio of transverse reinforcement in confined end regions, $f_{y h}$ the yield strength of confining reinforcement, $\varepsilon_{s m}$ the fracture strain of confining reinforcement and 0.005 was used based on reinforcing bars material test, $f_{c}$ ' the compressive strength of confined concrete. Figure 10-b shows stress-strain relations for confined concrete regions of the tested wall along with limit compressive strain, $\varepsilon_{c u}$, computed by Eq. 8 represented in the figure by red diamond. In the analysis, when the extreme compressive concrete fibre reached the limit compressive strain, $\varepsilon_{c u}$, the analysis was terminated and the corresponding drift was considered to be the ultimate drift.

The computed relations between lateral load, $Q$, and lateral drift angle are compared with the experimental hysteresis curves in Fig. 11. Although the computed peak load is slightly smaller than the experimental value, the computed backbone curve well simulates envelop of experimental results. It is noted that the flexural ultimate drift is especially well simulated (Tab. 6) with less computational effort compared to 3D FE analysis. 
Table 6 Comparison between experiment and fiber analysis for ultimate

$$
\text { drift point }
$$

\begin{tabular}{lccc}
\hline & \multicolumn{3}{c}{ Ultimate drift point } \\
\cline { 2 - 4 } Specimen & Experiment & Analysis & Ratio \\
& $R_{\text {exp }}(\%)(+) /(-)$ & $R_{\text {ana }}(\%)$ & $R_{\text {exp }} / R_{\text {ana }}$ \\
\hline BC40 & $4.00 /-2.75$ & 3.66 & 1.05 \\
BC80 & $2.00 /-2.00$ & 2.09 & 0.98 \\
NC40 & $2.38 /-2.00$ & 2.55 & 0.97 \\
NC80 & $1.50 /-1.50$ & 1.58 & 0.97 \\
\hline
\end{tabular}

Note: The ratio of experimental and analytical lateral drift was calculated based on the average value of the experimental ultimate drift between positive and negative loading directions.

\section{Conclusions}

Different numerical methods were used and summarized in this paper for simulating backbone curves and ultimate deformation capacity of reinforced concrete walls with confined boundaries.
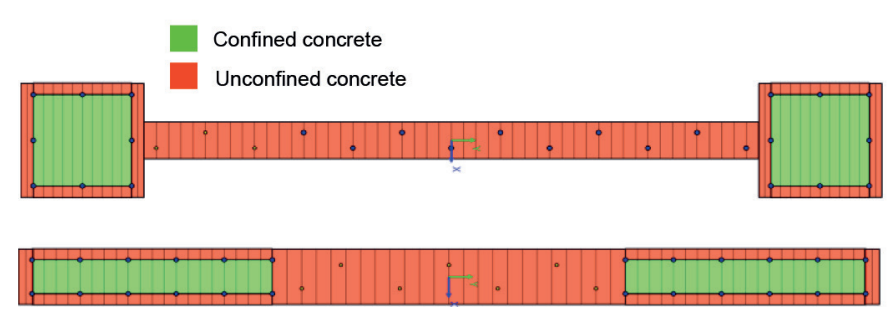

(a)

Fig. 10 (a) Walls sectional fiber meshing and (b) stress-strain relations for concrete with limit compressive strains
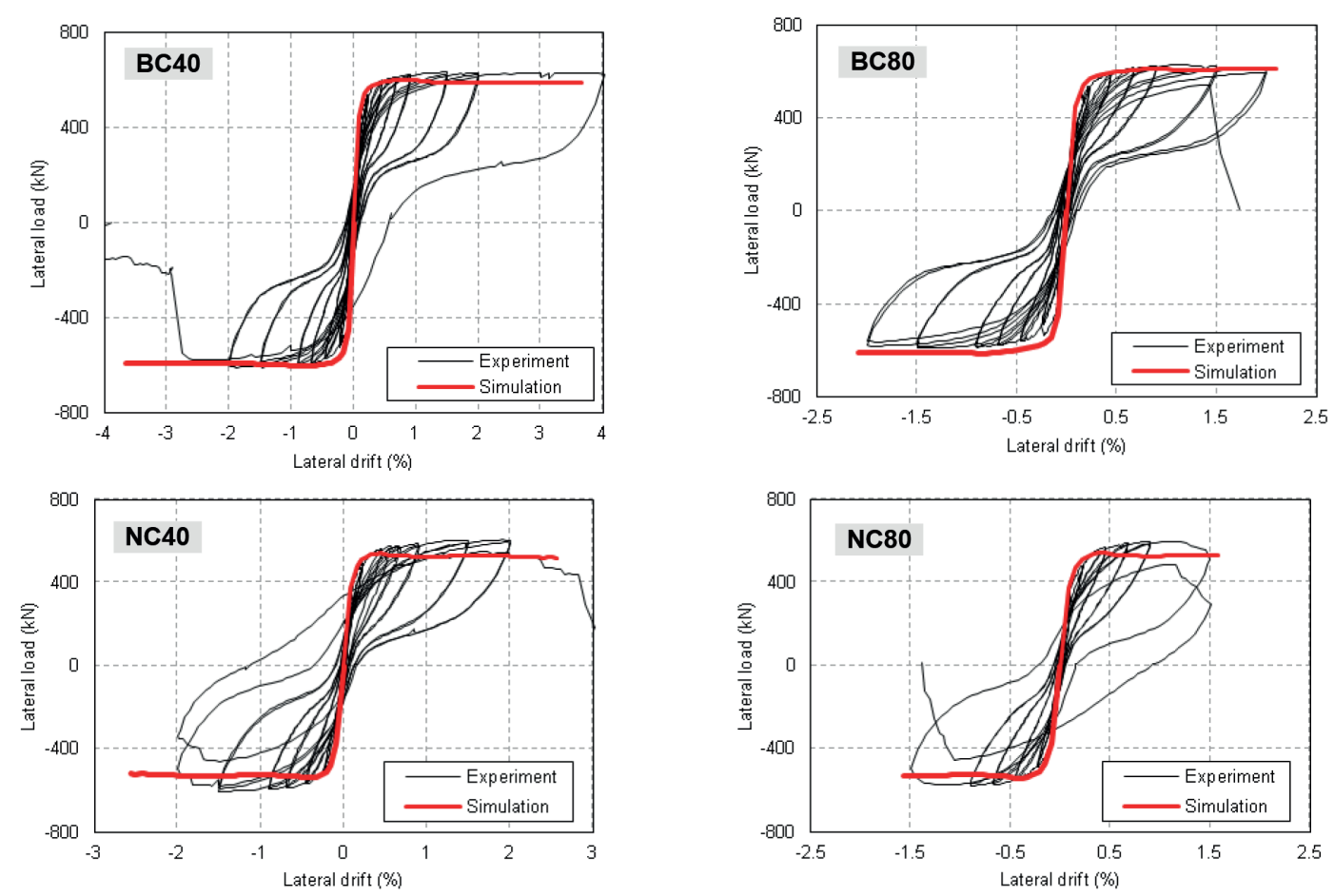

Fig. 11 Experimental hysteretic [11] and sectional analysis lateral load - drift angle relations observations regarding boundary columns that can effectively enhance the wall performance by increasing its ultimate deformation capacity and reducing damage level in the wall panel.

The built 2D and 3D FE models predicted damage pattern quite well, and has pridicted the ability of boundary columns in reducing damage level and crack distribution since boundary columns carry a large amount of axial force which reduce axial stress level in wall panels. In this manner, boundary columns can contribute effectivelly in preventing failure mode due to wall buckling, especially when subjected to high axial load.

The built 2D and 3D FE models were able to simulate the entire steps of the nonlinear behaviour of the concrete wall such as elastic region, cracking, steel yielding and peak load with relatively good accuracy. 3D model could simulate the ultimate deformation points with very good accuracy; however, the $3 \mathrm{D}$ nonlinear FE models are time consuming.

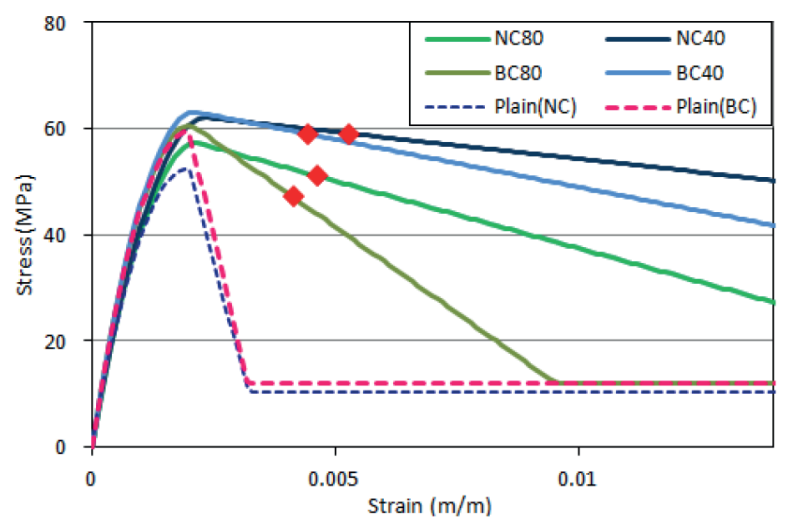

(b) 
The fibre model based on the plastic hinge length and moment-curvature analysis easy and interesting alternative for FE method for simulating the envelop response curve for RC walls with confined boundaries. In this manner, the limit compressive strain proposed by Mander et al. [28] is a good measure for the ultimate drift. The proposed method still needs to be tested with more experimental results.

For further improvement of the proposed method, it is necessary to study the premature failure of walls with a rectangular section under flexure such as shear sliding, global buckling of walls, and buckling of longitudinal reinforcement.

\section{Acknowledgement}

The project presented in this article was supported by the Japan Ministry of Land, Infrastructure, Transportation and Tourism (MLIT). The first author acknowledges the financial support from the Japan Ministry of Education, Culture, Sports, Science and Technology (MEXT).

\section{References}

[1] Portland Cement Association. "The Behavior of Reinforced Concrete Buildings in the Chilean Earthquakes of May 1960". p. 33. Skokie, 1963.

[2] Fintel, M. "Ductile Shear Walls in Earthquake Resistant Multistory Buildings". ACI Special Publication, 53(SP53-06), pp. 117-126. 1977. https://doi.org/10.14359/17695

[3] Thomsen, J. H., Wallace, J. W. "Displacement-based design of reinforced concrete structural walls: Experimental studies of walls with rectangular and T-shaped cross sections". Report No. CU/CEE-95/06, Department of Civil and Environmental Engineering, Clarkson University, Potsdam, 1995.

[4] Zhang, Y., Wang, Z. "Seismic Behavior of Reinforced Concrete Shear Walls Subjected to High Axial Loading". ACI Structural Journal, 97(5), pp. 739-750. 2000. https://doi.org/10.14359/8809

[5] Oh, Y. H., Han, S. W., Lee, L. H. "Effect of boundary element details on the seismic deformation capacity of structural walls". Earthquake Engineering \& Structural Dynamics, 31(8), pp. 1583-1602. 2002. https:// doi.org/10.1002/eqe.177

[6] Dazio, A., Beyer, K., Bachmann, H. "Quasi-static cyclic tests and plastic hinge analysis of RC structural walls". Engineering Structures, 31(7), pp. 1556-1571. 2009. https://doi.org/10.1016/j.engstruct.2009.02.018

[7] Taleb, R., Bechtoula, H., Sakashita, M., Bourahla, N., Kono, S. "Investigation of the shear behavior of multi-storyreinforced concrete walls with eccentric openings". Computers and Concrete, 10(4), pp. 361-377. 2012. https://doi.org/10.12989/cac.2012.10.4.361

[8] Yuniarsyah, E., Kono, S., Tani, M, Taleb, R, Sugimoto, K., Mukai, T. "Damage evaluation of lightly reinforced concrete walls in moment resisting frames under seismic loading". Engineering Structures, 132, pp. 349-371. 2017. https://doi.org/10.1016/j.engstruct.2016.11.047

[9] Bonelli, P., Restrepo, J. I., Boroschek, R., Carvallo, J. F. "The 2010 Great Chile Earthquake - Changes to Design Codes". In: Proceedings of the International Symposium on Engineering Lessons Learned from the 2011 Great East Japan Earthquake, March 1-4, 2012, Tokyo, Japan. pp. 1778-1787. 2012.

[10] Wallace, J. W., Massone L. M., Bonelli P., Dragovich J., Lagos R., Lüders, C., Moehle, J. "Damage and Implications for Seismic Design of RC Structural Wall Buildings". Earthquake Spectra, 28(S1), pp. S281S299. 2012. https://doi.org/10.1193/1.4000047
[11] Taleb, R., Kono, S., Tani, M. Sakashita, M. "Effects of End Regions Confinement on Seismic Performance of RC Cantilever Walls". In: $10^{\text {th }}$ U.S. National Conference on Earthquake Engineering, July 21-25, 2014, Anchorage, Alaska.

[12] Taleb, R., Tani, M., Kono, S. "Performance of Confined Boundary Regions of RC Walls under Cyclic Reversal Loadings". Journal of Advanced Concrete Technology, 14(4), pp. 108-124. 2016. https://doi. org $/ 10.3151 /$ jact.14.108

[13] Japan Building Disaster Prevention Association. "Standard for seismic evaluation of existing reinforced concrete buildings". Tokyo, 2001.

[14] National Institute for Land and Infrastructure Management. "Commentary of structural technique standard for buildings". Tokyo, 2015.

[15] ITOCHU Techno-Solutions Corporation. FINAL/V11, Finite elements analysis program for the nonlinear behavior of concrete structures. 2011.

[16] Elmorsi, M., Kianoush, M. R., Tso, W. K. "Modeling bond-slip deformations in reinforced concrete beam-column joints". Canadian Journal of Civil Engineering, 27(3), pp. 490-505. 2000. https://doi. org/10.1139/199-085

[17] Ciampi, V., Eligehausen, R., Bertero, V. V., Popov, E.,P. “Analytical model for concreteanchorages of reinforcing bars under generalized excitations". Report No. UCB/EERC 82-23, EERC, Berkeley, California, 1982.

[18] Naganuma, K., "Stress-strain Relationship of Concrete under Triaxial Compression". AIJ Journal of Structural and Construction Engineering, 474, pp. 163-170. 1995. (in Japanese)

[19] Kupfer, H., Hilsdorf, H. K. "Behavior of Concrete under Biaxial Stress”. ACI Journal Proceedings 66(8), pp. 656-666. 1969. https://doi. org/10.1139/199-085

[20] Naganuma, K., Yonezawa, K., Kurimoto, O., Eto, H. "Simulation of nonlinear Dynamic response of Reinforced Concrete Scaled Model Using Three-Dimensional Finite Element Method". In: $13^{\text {th }}$ WCEE Proceedings, Vancouver, B.C., Canada, Aug. 1-6, 2004, Paper 586.

[21] Naganuma, K., "Nonlinear Analytical Model for Reinforced Concrete Panels under In-Plane Stresses". AIJ Journal of Structural and Construction Engineering, 421, pp. 39-48. 1991. (in Japanese)

[22] Ottosen N. S. "A failure criterion for concrete". Journal of Engineering Mechanics, 103(EM4), pp. 527-535. 1977.

[23] Scott, B. D., Park R. Priestley, M. J. N. "Stress-strain behavior of concrete confined by overlapping hoops at low and high strain rates", ACI Journal Proceedings, 79(1), pp.13-27. 1982. https://doi.org/10.14359/10875

[24] Filippou, F. C., Popov, E. G., Bertero, V. V. "Effects of bond deterioration on hysteretic behavior of reinforced concrete joints". EERC Report No. UCB/EERC-83/19, Earthquake Engineering Research Center, University of California, Berkeley, 1983.

[25] Markeset, G., Hillerborg, A. "Softening of concrete in compression localization and size effects". Cement and Concrete Research, 25(4), pp. 702-708. 1995. https://doi.org/10.1016/0008-8846\%2895\%2900059-1

[26] Takahashi, S., Yoshida, K., Ichinose, T., Sanada, Y., Matsumoto, K., Fukuyama, H., Suwada, H. "Flexural drift capacity of reinforced concrete wall with limited confinement". ACI Structural Journal, 110(1), pp. 95-104. 2013. https://doi.org/10.14359/51684333

[27] Beyer, K., Dazio, A., Priestley. M. J. N. "Shear Deformations of Slender Reinforced Concrete Walls under Seismic Loading”. ACI Structural Journal, 108(2), pp. 167-177. 2011. https://doi.org/10.14359/51664252

[28] Mander, J. B., Priestley, M. J. N., Park, R. "Observed Stress-Strain Behavior of Confined Concrete". ASCE Journal of Structural Engineering, 114(8), pp. 1827-1849.1988. https://doi.org/10.1061/(ASCE) 0733-9445(1988)114:8(1827) 